\title{
RNF8 regulates active epigenetic modifications and escape gene activation from inactive sex chromosomes in post-meiotic spermatids
}

\author{
Ho-Su Sin, 1,2,3 Artem Barski, ${ }^{3,4,5}$ Fan Zhang, ${ }^{3,6}$ Andrey V. Kartashov, ${ }^{3,4,5}$ Andre Nussenzweig, \\ Junjie Chen, ${ }^{8}$ Paul R. Andreassen, ${ }^{4,5,6}$ and Satoshi H. Namekawa ${ }^{1,2,3,9}$ \\ ${ }^{1}$ Division of Reproductive Sciences, ${ }^{2}$ Division of Developmental Biology, Perinatal Institute, Cincinnati Children's Hospital \\ Medical Center, Cincinnati, Ohio 45229, USA; ${ }^{3}$ Department of Pediatrics, University of Cincinnati College of Medicine, \\ Cincinnati, Ohio 49229, USA; ${ }^{4}$ Division of Allergy and Immunology, ${ }^{5}$ Division of Human Genetics, ${ }^{6}$ Division of Experimental \\ Hematology and Cancer Biology, Cincinnati Children's Hospital Medical Center, Cincinnati, Ohio 45229, USA; ${ }^{7}$ Laboratory of \\ Genome Integrity, National Cancer Institute, National Institutes of Health, Bethesda, Maryland 20892, USA; ${ }^{8}$ Department of \\ Experimental Radiation Oncology, University of Texas M.D. Anderson Cancer Center, Houston, Texas 77030, USA
}

\begin{abstract}
Sex chromosomes are uniquely subject to chromosome-wide silencing during male meiosis, and silencing persists into post-meiotic spermatids. Against this background, a select set of sex chromosome-linked genes escapes silencing and is activated in post-meiotic spermatids. Here, we identify a novel mechanism that regulates escape gene activation in an environment of chromosome-wide silencing in murine germ cells. We show that RNF8dependent ubiquitination of histone $\mathrm{H} 2 \mathrm{~A}$ during meiosis establishes active epigenetic modifications, including dimethylation of H3K4 on the sex chromosomes. RNF8-dependent active epigenetic memory, defined by dimethylation of $\mathrm{H3K4}$, persists throughout meiotic division. Various active epigenetic modifications are subsequently established on the sex chromosomes in post-meiotic spermatids. These RNF8-dependent modifications include trimethylation of $\mathrm{H} 3 \mathrm{~K} 4$, histone lysine crotonylation $(\mathrm{Kcr})$, and incorporation of the histone variant H2AFZ. RNF8-dependent epigenetic programming regulates escape gene activation from inactive sex chromosomes in post-meiotic spermatids. Kcr accumulates at transcriptional start sites of sex-linked genes activated in an RNF8-dependent manner, and a chromatin conformational change is associated with RNF8dependent epigenetic programming. Furthermore, we demonstrate that this RNF8-dependent pathway is distinct from that which recognizes DNA double-strand breaks. Our results establish a novel connection between a DNA damage response factor (RNF8) and epigenetic programming, specifically in establishing active epigenetic modifications and gene activation.
\end{abstract}

[Keywords: DNA damage response; epigenetics; escape genes; germ cells; sex chromosomes]

Supplemental material is available for this article.

Received August 1, 2012; revised version accepted November 2, 2012.

Sex chromosomes go through unique epigenetic programming during reproduction and development. Mammalian sex chromosomes are an excellent model system to understand the pivotal roles of epigenetic programming in development. Importantly, sex chromosomes precisely recapitulate stereotypical epigenetic programming in a timely and spatially coordinated manner. In females, one of the $\mathrm{X}$ chromosomes is inactivated for dosage compensation of X-linked genes (Gendrel and Heard 2011; Lee 2011; Payer et al. 2011). In males, sex chromosomes are inactivated

${ }^{9}$ Corresponding author

E-mail satoshi.namekawa@cchmc.org

Article is online at http://www.genesdev.org/cgi/doi/10.1101/gad.202713.112. from meiosis to spermiogenesis in a process that is essential for germ cell development (Turner 2007; Yan and McCarrey 2009; Inagaki et al. 2010; Ichijima et al. 2012). Against this background, many X-linked microRNAs escape silencing in meiosis (Song et al. 2009), and a select set of sex-linked genes escapes silencing and is activated in post-meiotic spermatids (Namekawa et al. 2006; Mueller et al. 2008; Berletch et al. 2010; Sin et al. 2012). Although underlying mechanisms of chromosome-wide silencing in both females and males are being gradually elucidated, the mechanism by which essential genes achieve gene expression has remained an unsolved mystery.

Meiotic sex chromosomes provide a unique opportunity to dissect the process of epigenetic programming. 
Sin et al.

Following the initiation of meiotic sex chromosome inactivation (MSCI), various epigenetic modifications are established gradually on the sex chromosomes in a coordinated manner, and the stage of spermatogenesis can be precisely defined. Epigenetic modifications on the sex chromosomes are maintained through meiotic cell division into spermatids, implying the inheritance of an epigenetic memory following meiosis (Turner 2007; Payer et al. 2011).

An essential step in the initiation of MSCI is the recognition of a chromosome-wide domain by an action of the DNA damage response (DDR) pathway, centered on $\gamma \mathrm{H} 2 \mathrm{AX}$ and its binding partner MDC1 at the early pachytene stage (Ichijima et al. 2011). An interacting partner of MDC1, the ubiquitin ligase RNF8, is essential in the somatic DDR (Huen et al. 2007; Kolas et al. 2007; Mailand et al. 2007) and is responsible for histone H2A ubiquitination on the sex chromosomes at the onset of MSCI (Fig. 1A-C; Lu et al. 2010; Santos et al. 2010). Although Rnf8 knockout (KO) mice are sterile, RNF8 does not have a function in gene silencing (Lu et al. 2010) or MDC1-dependent chromosome-wide amplification of the $\gamma \mathrm{H} 2 \mathrm{AX}$ signal (Ichijima et al. 2011). The role of histone H2A ubiquitination on the sex chromosomes remains unknown.

Initiation of MSCI is followed by the establishment of various epigenetic modifications, with the entire domain of the sex chromosomes treated distinctly from the rest of the genome. Of note, sex chromosomes are illuminated with silent modifications that include H3K9 methylation and heterochromatin proteins (Namekawa et al. 2006; Turner et al. 2006). The sex chromosomes are also marked by epigenetic modifications that are associated with active transcription, including dimethylation of histone H3 Lys 4 (H3K4me2) (Baarends et al. 2007). Given the dynamic epigenetic changes on the sex chromosomes after the establishment of RNF8-dependent histone H2A ubiquitination, we sought to determine the role of RNF8 in epigenetic programming. Here we show that multiple active epigenetic marks are established in an RNF8dependent manner after completion of meiotic prophase. Furthermore, we show that an RNF8-dependent epigenetic memory involving active marks persists through meiotic division and regulates escape gene activation on the sex chromosomes in post-meiotic spermatids. Our results reveal a novel role of RNF8 in epigenetic programming apart from its function in DNA damage signaling in somatic cells.

\section{Results}

RNF8 regulates active epigenetic modifications on the sex chromosomes in meiosis

To determine whether RNF8 has a role in epigenetic programming on sex chromosomes, we tested various kinds of histone modifications during spermatogenesis by immunostaining cells from wild-type and Rnf8-KO mice (Fig. 1). Following RNF8-dependent ubiquitination of histone H2A on the sex chromosomes (Fig. 1B,C; Supplemental Fig. S1), we found that accumulation of monomethylated histone H4 Lys 20 (H4K20me1) is dependent on RNF8 from the early pachytene stage (when homologous chromosome synapsis completes) to the middiplotene stage (when homologous chromosomes start to segregate) in meiotic prophase (Fig. 1D,E; Supplemental Fig. S2). There was $100 \%$ depletion $(n>100)$ in the $R n f 8$ KO. H4K20me1 is associated with active transcription (Talasz et al. 2005; Barski et al. 2007) and is also implicated in gene silencing (Beck et al. 2012). H4K20me1 localizes on inactive sex chromosomes in males (van der Heijden et al. 2007) and on inactive $X$ chromosome in females (Kohlmaier et al. 2004). On male meiotic sex chromosomes, the accumulation of H4K20mel is concomitant
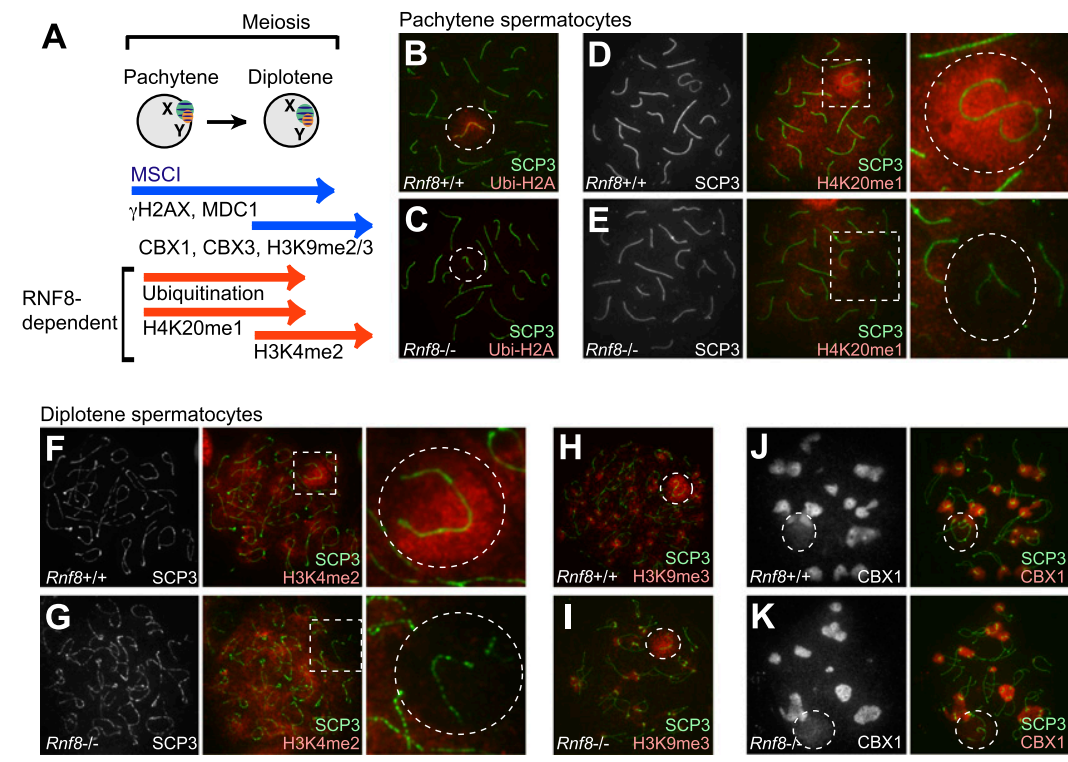

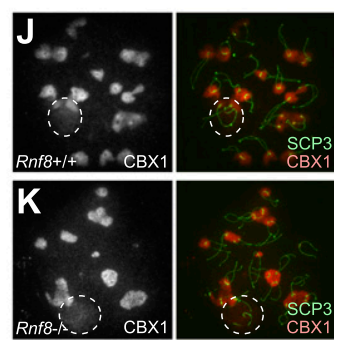

Figure 1. RNF8 is required for establishing active epigenetic modifications on the sex chromosomes. (A) Schematic of sex chromosome inactivation in meiosis and a summary of the RNF8-dependent modifications that we identified here (red). $(B-G)$ RNF8-dependent histone modifications in primary spermatocytes were identified by immunostaining. SCP3 is a marker of meiotic chromosome axes. Regions inside the dotted squares are magnified in the panels on the right. Locations of $\mathrm{XY}$ bodies are highlighted with dotted circles. $(H-K)$ RNF8 does not regulate silent histone modifications. All images are immunostaining of meiotic chromosome spreads. 
with ubiquitinated $\mathrm{H} 2 \mathrm{~A}$ from the early pachytene stage to the mid-diplotene stage.

Furthermore, H3K4me2, a representative modification associated with active transcription, starts to accumulate on the sex chromosomes after the diplotene stage (Fig. 1F; Baarends et al. 2007), while this accumulation is largely depleted in all cells $(n>100)$ in the Rnf8-KO (Fig. 1G). Conversely, silent epigenetic modifications-including H3K9 methylation and heterochromatin proteins CBX1 and CBX3-that are established on the sex chromosomes are not affected in the Rnf8-KO (Fig. $1 \mathrm{H}-\mathrm{K}_{\text {; }}$ data not shown). This suggests that RNF8-dependent epigenetic programming specifically regulates active epigenetic modifications. Based on the timing of appearance of RNF8-dependent modifications, our results suggest that $\mathrm{H} 3 \mathrm{~K} 4 \mathrm{me} 2$ is established downstream from RNF8-dependent ubiquitinated H2A and H4K20me1 on the sex chromosomes.

\section{RNF8-dependent active epigenetic memory persists into post-meiotic spermatids}

Depletion of H3K4me2 on sex chromosomes in the Rnf8$\mathrm{KO}$ persists through meiotic divisions into post-meiotic round spermatids. In round spermatids, silent sex chro- mosomes form DAPI-discernible heterochromatin, termed post-meiotic sex chromatin (PMSC). Chromosome-wide silencing of the sex chromosomes is largely maintained after meiosis to round spermatids, except for the activation of a class of genes that escapes chromosome-wide silencing (Fig. 2A; Namekawa et al. 2006). While enrichment of $\mathrm{H} 3 \mathrm{~K} 4 \mathrm{me} 2$ on the sex chromosomes persists from meiosis to round spermatids in the wild type (Fig. 2B), $\mathrm{H} 3 \mathrm{~K} 4 \mathrm{me} 2$ is continuously depleted from PMSC in the Rnf8-KO (100\% depletion $n>100$ ) (Fig. 2C). Although PMSC is DAPI-discernible, the position of the sex chromosomes was further confirmed by DNA fluorescent in situ hybridizatoin (FISH) using X- or Y-chromosome paints (Supplemental Fig. S3). H3K4me3 does not accumulate on the sex chromosomes in meiosis but is present on PMSC in the wild type in round spermatids (Fig. 2D). $\mathrm{H} 3 \mathrm{~K} 4 \mathrm{me} 3$ is significantly depleted from PMSC in the Rnf8-KO (Fig. 2E). Of note, active epigenetic modifications that are known to specifically accumulate on PMSC in the wild type, such as histone lysine crotonylation (Kcr) (Tan et al. 2011) and histone variant H2AFZ (Greaves et al. 2006), were substantially diminished in the Rnf8-KO (Fig. 2F-I). These results suggest that RNF8-dependent epigenetic memory persists through meiotic divisions into
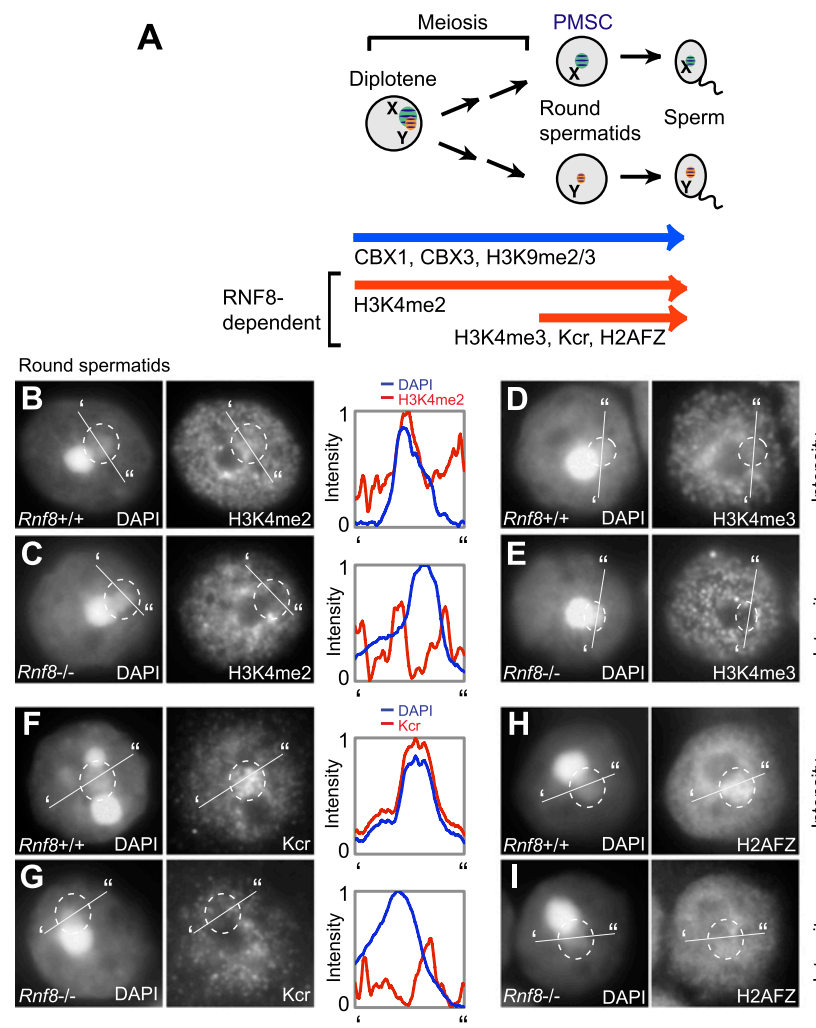
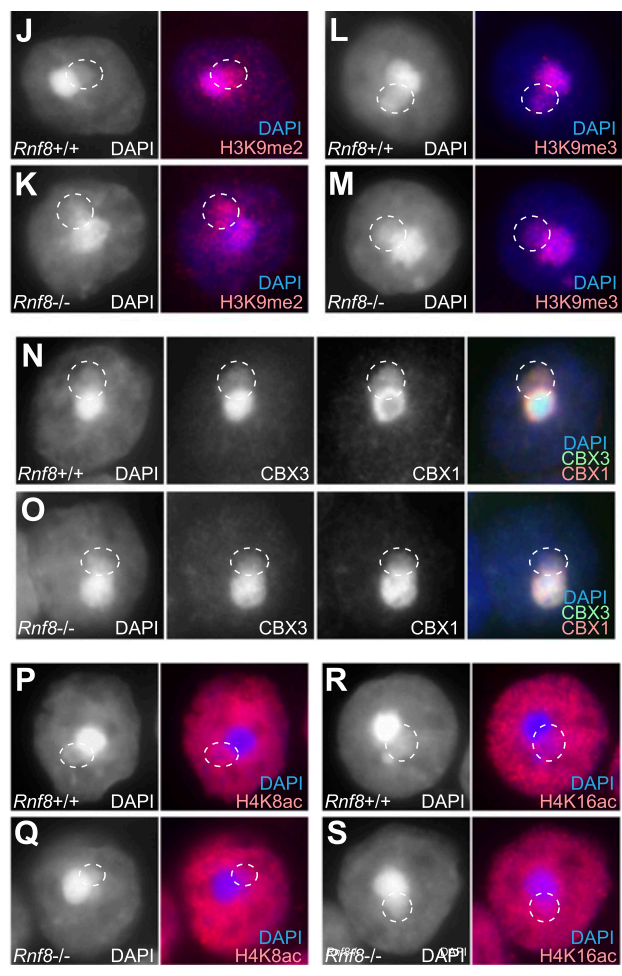

Figure 2. RNF8-dependent active epigenetic memory persists into post-meiotic spermatids. (A) Schematic of sex chromosome inactivation in the round spermatids and a summary of RNF8-dependent modifications that we identified here (red). (B-I) RNF8dependent modifications are identified in round spermatids by immunostaining. Locations of PMSC are highlighted with dotted circles. The intensity of immunostaining is quantified by densitometry across the indicated path (' to ") and are plotted in the relative intensity range of $0-1$. ( $J-O)$ Silent histone modifications on PMSC are not regulated by RNF8. (P-S) H4K8 acetylation and H4K16 acetylation on PMSC are not regulated by RNF8. 
round spermatids and establishes these modifications specifically on PMSC, although molecular links between these modifications remain to be determined. Given the RNF8-dependent accumulation of H3K4me2 from meiosis to round spermatids, we propose that $\mathrm{H} 3 \mathrm{~K} 4 \mathrm{me} 2$ serves as a persistent RNF8-dependent epigenetic memory maintained through meiotic divisions to establish specific active modifications on PMSC.

Alternatively, silent epigenetic modifications on the sex chromosomes, such as $\mathrm{H} 3 \mathrm{~K} 9 \mathrm{me} 2$, trimethylation of histone H3 Lys 9 (H3K9me3), and heterochromatin proteins CBX1 and CBX3, are not altered on PMSC in the Rnf8-KO (Fig. 2J-O), consistent with the normal accumulation of these modifications in meiosis in the Rnf8-KO (Fig. 1H-K). To further determine the selectivity of the RNF8 pathway in epigenetic programming, we examined profiles of histone acetylation. Histone acetylation is another form of active epigenetic modification associated with active transcription. H4K8 acetylation and H4K16 acetylation are excluded from meiotic sex chromosomes (data not shown) but are present on PMSC in the wild type (Fig. 2P,R; Greaves et al. 2006). These modifications accumulate normally onto the PMSC in round spermatids of the Rnf8-KO (Fig. $2 \mathrm{Q}, \mathrm{S})$. Therefore, H4K8 acetylation and H4K16 acetylation are not regulated by RNF8. These results demonstrate selectivity of the effects of the RNF8-dependent pathway to a certain class of active epigenetic modifi- cations, including H3K4 methylation, Kcr, and H2AFZ (Supplemental Fig. S3I).

\section{RNF8 regulates escape gene activation from the sex chromosomes in round spermatids}

The above results revealed specific alterations of a class of active epigenetic modifications on the sex chromosomes, raising the possibility of altered gene expression on the sex chromosome in the Rnf8-KO. To determine whether RNF8 is involved in gene activation of sex-linked genes, we performed microarray analysis using Affymetrix Gene 1.0 ST arrays with purified pachytene spermatocytes and round spermatids. In the pachytene spermatocytes, the differences between the wild type and Rnf8-KO are modest, and only three gene probes are altered more than twofold (Fig. 3A; Supplemental Table S1). However, we identified a larger set of gene probes that is downregulated more than twofold in the round spermatids of the $R n f 8-\mathrm{KO}$, relative to wild-type cells (Fig. 3B; Supplemental Table S2). The vast majority of these gene probes is located on either the $\mathrm{X}$ or $\mathrm{Y}$ chromosomes (Fig. 3C), consistent with the cytological observation of specific depletion of active epigenetic modifications from the sex chromosomes in the Rnf8-KO. Furthermore, these gene probes, which are expressed in an RNF8-dependent manner, are distributed along the $\mathrm{X}$ chromosome (Fig. 3D). This suggests that gene activation by an RNF8-dependent
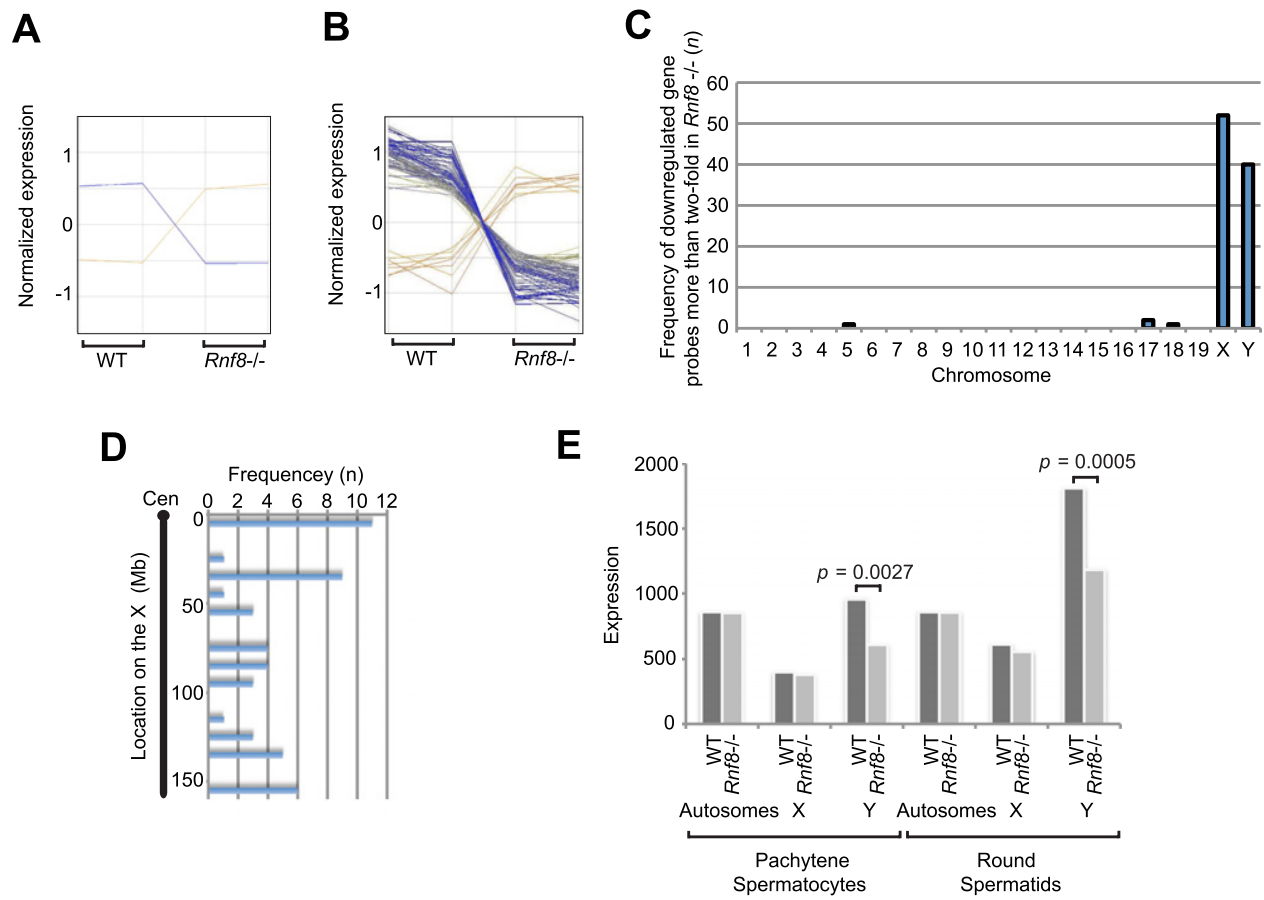

Figure 3. RNF8 is required for sex-linked gene activation in round spermatids. A microarray analysis of purified pachytene spermatocytes and round spermatids is shown here. $(A, B)$ Gene probes that show a more than twofold change with statistical significance $(P<0.05$, unpaired $t$-test $)$ after multiple testing correction are shown. $(A)$ Pachytene spermatocytes. $(B)$ Round spermatids. $(C)$ Chromosomal distribution of down-regulated gene probes in the Rnf8-KO. (D) Frequency of down-regulated gene probes every 10 $\mathrm{Mb}$ along the $\mathrm{X}$ chromosome. (E) Average expression of the $\mathrm{X}$ and $\mathrm{Y}$ chromosomes and autosomes in pachytene spermatocytes and round spermatids. $P$-values are derived from unpaired $t$-tests. 
pathway occurs throughout the X chromosome. Among these RNF8-dependent gene probes, we eliminated probes that redundantly recognize single genes and probes that match intergenic regions. We identified $38 \mathrm{X}$-linked genes and 13 Y-linked genes regulated by RNF8 (Supplemental Table S3).

A selective set of sex-linked genes tends to escape postmeiotic silencing and is activated in round spermatids (Namekawa et al. 2006; Mueller et al. 2008; Sin et al. 2012). In this study, we hereafter refer to this class of sexlinked genes as "escape genes" and this process as "escape gene activation." RNF8-dependent escape genes belong to this class of reproduction genes that are expressed predominantly in the testis (Supplemental Figs. S4, S5A). One example of RNF8-dependent Y-linked genes is the Ssty gene family, which is associated with low sperm motility and low sperm counts that cause male infertility in mice (Toure et al. 2005; Ward and Burgoyne 2006). Examples of RNF8-dependent X-linked genes are Rhox11 and Samt1, which are specifically activated at late stages of spermatogenesis in mice (Hogeveen and Sassone-Corsi 2005; Maclean et al. 2005; Yogo et al. 2012). As with the wild type, however, average expression of the $\mathrm{X}$ and $\mathrm{Y}$ chromosomes is increased from the pachytene spermatocyte stage to the round spermatid stage in the Rnf8-KO (Fig. 3E). These results suggest that activation of a subset of sex-linked genes occurs independently of RNF8 and that RNF8 controls a specific subset of escape genes in the round spermatids. This could account for why the average expression of all X-linked genes is not significantly affected in the Rnf8-KO (Fig. 3E) despite the significant down-regulation of escape genes (Fig. 3C) because the number of RNF8-dependent escape genes is small compared with the number of all X-linked genes. Conversely, the average expression of all Y-linked genes is significantly affected in the round spermatids of the Rnf8-KO (Fig. 3E).

\section{Chromatin conformational change is associated with RNF8-dependent epigenetic programming}

The previous identification of Kcr enrichment at sites of active X-linked genes in round spermatids (Tan et al. 2011) prompted us to examine the genomic distribution of Kcr by chromatin immunoprecipitation (ChIP) coupled with deep sequencing (ChIP-seq) data, and its association with RNF8-dependent escape genes using our current and previous microarray data (Namekawa et al. 2006). Actively transcribed genes (i.e., "present genes" in the microarray analysis) show a higher level of Kcr around transcription start sites (TSSs) compared with nonexpressed genes (absent genes). This suggests that accumulation of Kcr is associated with transcriptionally active genes in the genome (Fig. 4A). Kcr is highly enriched at the TSSs of RNF8-dependent escape genes such as Prame (Fig. 4B). Notably, RNF8-dependent escape genes show a distinct pattern of Kcr distribution around the TSSs. Compared with X-linked genes that are subject to post-meiotic silencing, Kcr highly accumulates around TSSs of RNF8dependent genes (Fig. 4C). The ChIP-seq experiment was
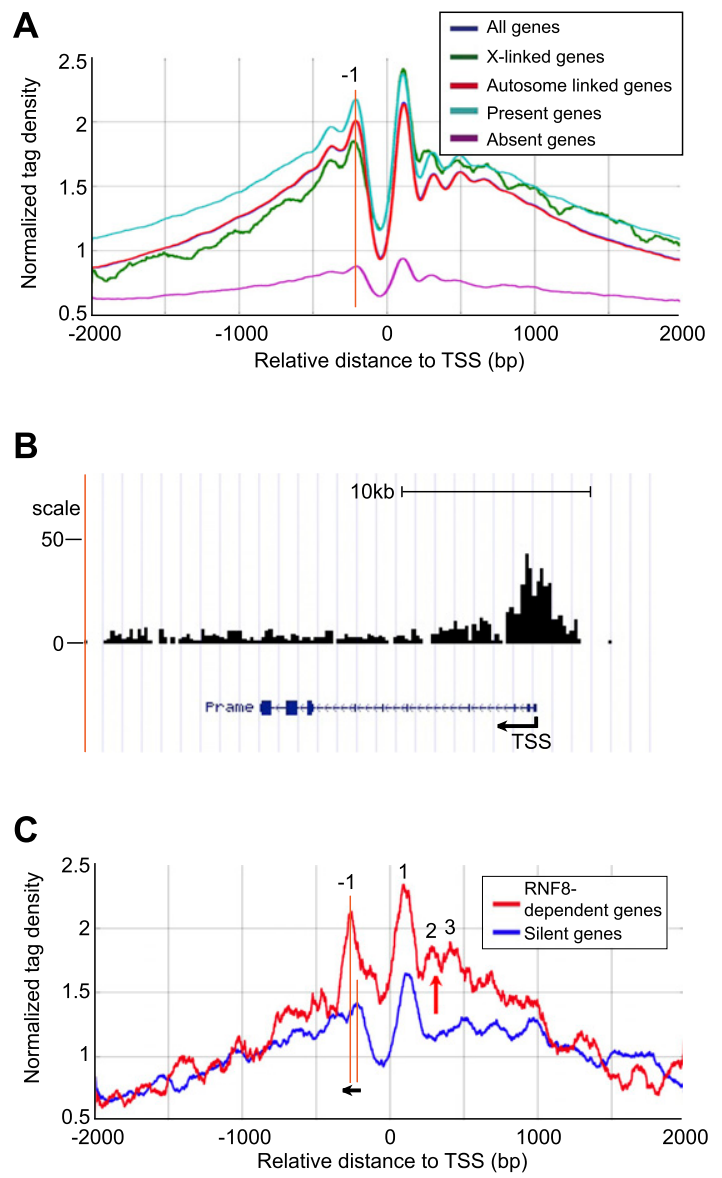

Figure 4. Kcr accumulates at TSSs of RNF8-dependent escape genes on the $\mathrm{X}$ chromosome. (A) Average normalized read density of Kcr around TSSs in round spermatids. Kcr is associated with high expression in round spermatids. The position of the first nucleosome upstream of TSSs is indicated. The average expression of all genes almost overlaps with those of autosomelinked genes. Present and absent genes are based on the call of the microarray analysis. (B) ChIP-seq profile of Kcr in the $\mathrm{X}$-linked Prame gene locus. (C) Average normalized read density of Kcr around TSSs is plotted. The profiles of RNF8-dependent escape genes and silent genes subject to post-meiotic silencing are shown. The nucleosome positions are indicated. (Black arrow) A shift of $\sim 50 \mathrm{bp}$ of the first nucleosome upstream of TSSs; (red arrow) enrichment of Kcr in the first three nucleosomes.

performed after micrococcal nuclease digestion without fixation (native ChIP), and peaks near the TSSs correspond to the position of nucleosomes. The position of the first nucleosome upstream of TSSs was shifted $\sim 50$ base pairs (bp) in the upstream direction in RNF8-dependent escape genes, as compared with genes that remain silent in round spermatids (black arrow in Fig. 4C). This feature is not associated with other active genes in the round spermatids (Fig. 4A). Therefore, the nucleosome-free region adjacent to TSSs, where RNA polymerase II is loaded (Schones et al. 2008), is larger in the RNF8-dependent escape genes. This suggests that an open chromatin conformation facilitates loading of RNA polymerase II and transcription factors. Another signature is enrichment of 
Sin et al.

Kcr in the first three nucleosomes (red arrow in Fig. 4C). Furthermore, we confirmed that Kcr enrichment at TSSs is RNF8-dependent (Supplemental Fig. S5B). These results suggest that a chromatin conformational change is associated with RNF8-dependent epigenetic programming.

\section{RNF8 may not be directly associated with the histone-to-protamine exchange}

Taken together, we conclude that the primary role of RNF8 in spermatogenesis is epigenetic programming on the sex chromosomes and that the RNF8-dependent pathway is required for activation of a certain class of escape genes from otherwise inactive sex chromosomes in round spermatids. Insufficiency of sex chromosome-linked genes likely accounts for infertility in the Rnf8-KO because many reproduction genes are sex-linked and expressed in round spermatids (Zhang et al. 2010; Sin et al. 2012). A previous study suggested that RNF8dependent ubiquitination in the late stage of spermiogenesis is required for global H4K16 acetylation and for the histone-to-protamine exchange that is necessary for sperm condensation (Lu et al. 2010). However, using the same line of Rnf8-KO mice, we did not see any abnormality in global H4K16 acetylation or in the histone-toprotamine exchange in the Rnf8-KO (Supplemental Figs. S6, S7), although we also confirmed the global depletion of ubiquitinated $\mathrm{H} 2 \mathrm{~A}$ in the elongating spermatids of the Rnf8-KO (Supplemental Fig. S1). Therefore, ubiquitinated H2A may not be directly associated with H4K16 acetylation or with the histone-to-protamine exchange.

The novel role of RNF8 on the sex chromosomes is distinct from its role in the DDR in somatic cells

Identification of this novel RNF8-dependent pathway prompted us to further dissect it and investigate its relationship to the canonical DDR pathway in which
RNF8 responds to DNA double-strand breaks (DSBs). In somatic cells, RNF8-mediated ubiquitination recruits various DDR factors, including p53-binding protein 1 (53BP1) and RAP80 (Huen et al. 2007; Kolas et al. 2007; Mailand et al. 2007; Wang and Elledge 2007). On meiotic sex chromosomes, we found that 53BP1 recruitment occurs over the entire chromosome-wide domain in the wild type but is confined to the axis of the sex chromosomes in the Rnf8-KO (Fig. 5A,B). RAP80, a DDR factor that binds to ubiquitin generated in a RNF8-dependent manner (Mailand et al. 2007; Wu et al. 2009; Zhang et al. 2012) and transmits DDR signaling in somatic cells, is absent on meiotic sex chromosomes; however, it accumulates on both ends of all chromosomes regardless of the genotype of RNF8 (Fig. 5C,D). This suggests that RAP80 is unlikely to be involved in the regulation of sex chromosomes, in contrast to its role in the somatic DDR.

We then further examined the potential role of 53BP1 in the establishment of active epigenetic modifications. In the $53 b p 1-\mathrm{KO}, \mathrm{H} 4 \mathrm{~K} 20 \mathrm{me} 1$ and $\mathrm{H} 3 \mathrm{~K} 4 \mathrm{me} 2$ are established normally on the sex chromosomes in meiosis (Fig. 5E,F). Additionally, H3K4me2 persists into PMSC (Fig. 5G), and H3K4me3, Kcr, and H2AFZ are established normally on PMSC in the round spermatids (Fig. 5H-J). These results indicate that RNF8-dependent epigenetic programming is not affected in the $53 \mathrm{bp} 1-\mathrm{KO}$. These results are in line with the fecundity of the 53bp1-KO (Ward et al. 2003). Thus, while 53BP1 accumulates on sex chromosomes in an RNF8-dependent manner, it does not regulate the accumulation of active histone modifications. These results suggest that the role of RNF8 in establishing active histone modifications on sex chromosomes is distinct from the role of RNF8 in recognizing DSBs in the somatic DDR.

To directly test the role of RNF8 in the regulation of epigenetic modifications in the context of the DDR in somatic cells, we examined human U2OS cells subjected
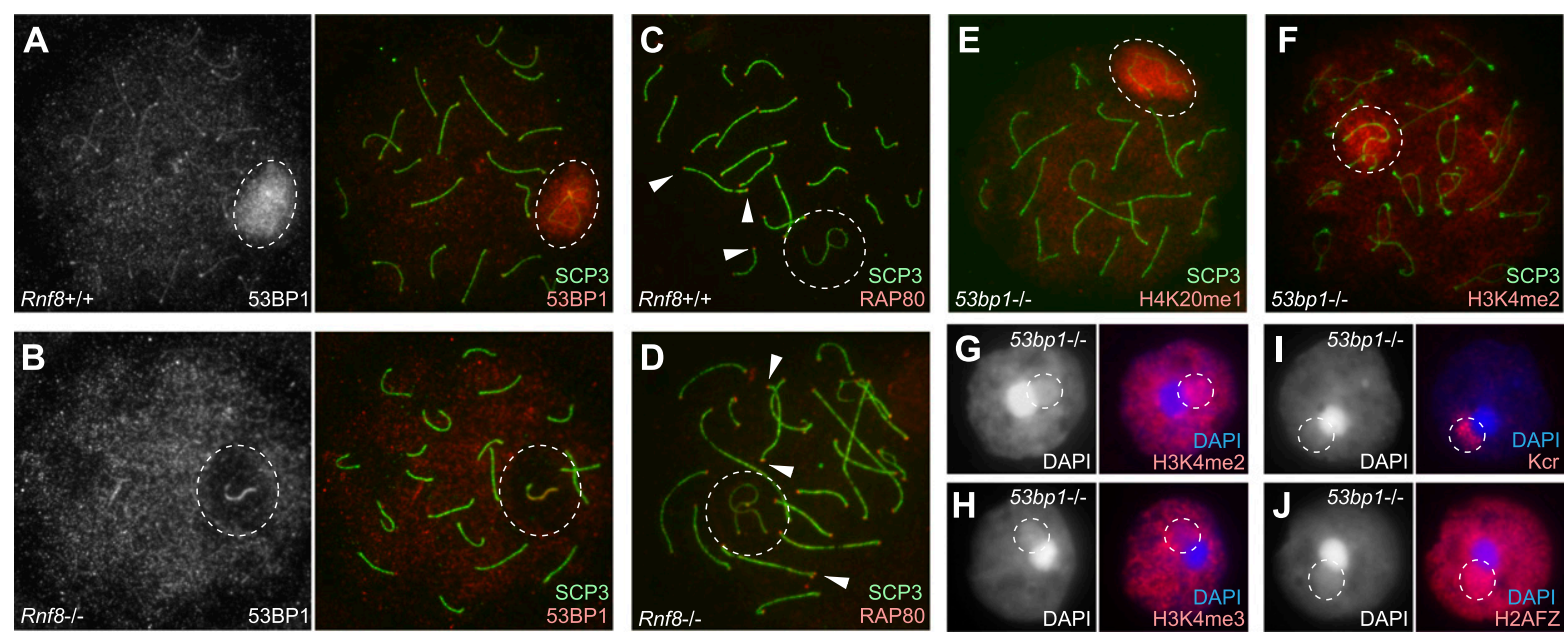

Figure 5. 53BP1 is not required for RNF8-dependent epigenetic programming. $(A-D)$ Examination of RNF8-dependent regulation of 53BP1 and RAP80 on sex chromosomes by immunostaining. Arrowheads indicate examples of chromosome ends that have RAP80 signals. $(E, F)$ Immunostaining of meiotic chromosome spreads of the $53 \mathrm{bp} 1$-KO with the indicated antibodies. $(G-J)$ Immunostaining of round spermatids of the $53 \mathrm{bp} 1-\mathrm{KO}$ with the indicated antibodies. 
to laser microirradiation to induce DSB stripes. A widely accepted marker of DSBs, $\gamma$-H2AX (Rothkamm and Lobrich 2003), was induced either with or without siRNA-mediated depletion of RNF8. Although 53BP1 and RAP80 were recruited to laser-induced stripes in U2OS cells in an RNF8-dependent manner (Fig. 6A-D), we did not see any accumulation of epigenetic modifications-including $\mathrm{H} 4 \mathrm{~K} 20 \mathrm{me} 1, \mathrm{H} 3 \mathrm{~K} 4 \mathrm{me} 2$, and $\mathrm{H} 3 \mathrm{~K} 4 \mathrm{me} 3$ - that are, in contrast, dependent on RNF8 on meiotic sex chromosomes (Fig. 6E,F). These results further support the possibility that RNF8 has a distinct role on meiotic sex chromosomes in addition to its well-known function of recognizing DSBs in the somatic DDR (Fig. 6G).

\section{Discussion}

In this study, we identified a novel RNF8-dependent pathway that establishes active epigenetic modifications and regulates escape gene activation from otherwise inactive sex chromosomes in round spermatids. To our knowledge, this represents the first mechanistic insight into the regulation of escape gene activation in postmeiotic spermatids. Importantly, while RNF8 functionally interacts with MDC1 during the somatic DDR, these proteins have different functions in male meiosis. RNF8 is associated with activation, whereas, in contrast, MDC1 is associated with silencing. Thus, together, DDR factors have a broad role in epigenetic programming and in controlling gene expression on the sex chromosomes.

Our previous study showed that RNF8 is not involved in the MDC1-dependent amplification of $\gamma \mathrm{H} 2 \mathrm{AX}$, which is an essential step in the recognition of the chromosomewide domain of sex chromosomes and in the initiation of MSCI (Ichijima et al. 2011). This is of interest because RNF8 regulates the somatic DDR by binding to MDC1 (Huen et al. 2007; Kolas et al. 2007; Mailand et al. 2007; Shanbhag et al. 2010). In meiosis, it is conceivable that recruitment of RNF8 to the sex chromosomes could be mediated through its binding to MDC1 after completion of MDC1-dependent $\gamma \mathrm{H} 2 \mathrm{AX}$ amplification. Indeed, RNF8-dependent ubiquitination of H2A promptly follows MDC1-dependent amplification of $\gamma \mathrm{H} 2 \mathrm{AX}$ at the early pachytene stage. Whether RNF8 function on the sex chromosomes in meiosis is dependent on MDC1 cannot be analyzed, however, due to meiotic arrest at the midpachytene stage in Mdc1 knockout mice (Ichijima et al. 2011).

Importantly, the role of RNF8 in mediating ubiquitination of $\mathrm{H} 2 \mathrm{~A}$ in the context of gene activation in round spermatids contrasts with a previous study implicating RNF8 in gene silencing in the somatic DDR (Shanbhag et al. 2010). Furthermore, the identification of ubiquitinated H2A in the context of gene activation is also in marked contrast to the prevailing view of the role of ubiquitinated $\mathrm{H} 2 \mathrm{~A}$ in gene silencing. Ubiquitination of $\mathrm{H} 2 \mathrm{~A}$ can also be mediated by another E3 ubiquitin ligase, RNF2/Ring1b, which is a subunit of Polycomb-repressive complex 1 (PRC1) and is involved in female X-chromosome inactivation (de Napoles et al. 2004). PRC1 mediates chromatin compaction (Francis et al. 2004), and RNF2mediated monoubiquitination of $\mathrm{H} 2 \mathrm{~A}$ is associated with gene silencing. Based on these views, ubiquitinated $\mathrm{H} 2 \mathrm{~A}$ on meiotic sex chromosomes has been considered to have functions in gene silencing (Baarends et al. 2005; An et al. 2010). In contrast, we revealed a novel role for ubiquitinated $\mathrm{H} 2 \mathrm{~A}$ in gene activation in our study. It is conceivable that, although RNF2 and RNF8 both mediate ubiquitination of $\mathrm{H} 2 \mathrm{~A}$, it is the nature of the ubiquitin linkage that determines whether such signaling results in gene silencing or activation. One potential difference is that RNF8 mediates polyubiquitin linkages (Feng and Chen 2012), whereas RNF2 mediates monoubiquitination of H2A. Further characterization of downstream signaling will distinguish the molecular basis by which RNF2 and RNF8 ubiquitination mediates gene silencing or activation.

In comparison with RNF2-mediated ubiquitination of $\mathrm{H} 2 \mathrm{~A}, \mathrm{RNF} 8-$ mediated ubiquitination of H2A is associated with an open chromatin conformation (Luijsterburg et al. 2012). This open chromatin conformation could be a prerequisite for the recruitment of downstream DDR factors in the somatic DDR. Therefore, an open chromatin structure is likely also associated with RNF8mediated ubiquitination of $\mathrm{H} 2 \mathrm{~A}$ on the sex chromosomes.
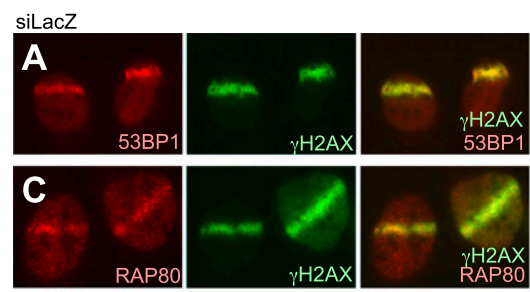

siLacZ
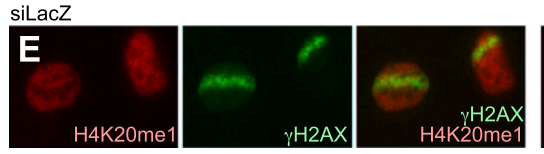

SiRNF8

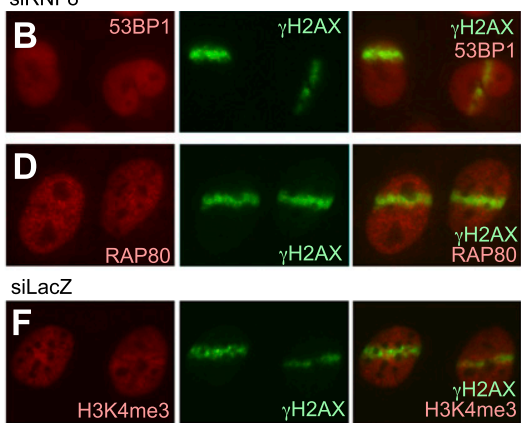

G

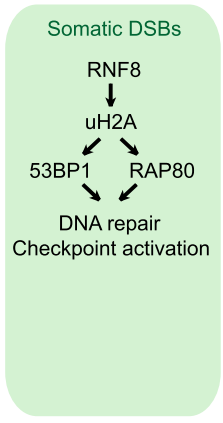

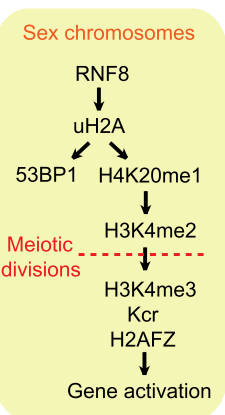

Figure 6. A novel RNF8-dependent pathway on sex chromosomes has distinct features compared with the pathway that recognizes somatic DSBs. $(A-F)$ Accumulation of DDR proteins but not active histone marks, which occur on sex chromosomes, in microirradiated U2OS cells. $(G)$ Model of two distinct RNF8-dependent pathways. 
Since ubiquitinated H2A and H4K20me1 are concomitant on the meiotic sex chromosomes, it would be intriguing to examine whether a histone methyltransferase for H4K20mel is recruited to the open chromatin associated with ubiquitinated $\mathrm{H} 2 \mathrm{~A}$ on sex chromosomes. SET8 is a possible candidate, since it is currently the only methyltransferase implicated in mediating H4K20me1 (Beck et al. 2012).

An important difference between the role of RNF8 in the somatic DDR and on the sex chromosomes is the nature of the factors that are subsequently recruited. Our analysis of the 53bp1-KO mice demonstrates that subsequent recruitment of this DDR factor is not involved in RNF8-dependent epigenetic programming on the sex chromosomes. Furthermore, while RAP80 binds to ubiquitinated $\mathrm{H} 2 \mathrm{~A}$ that is generated in an RNF8-dependent fashion in the somatic DDR, RAP80 is not specifically recruited to meiotic sex chromosomes. Also, in the somatic DDR, another E3 ubiquitin ligase, RNF168, amplifies polyubiquitin chains on H2A that are initiated by RNF8. This amplification step is essential to the recruitment of downstream DDR factors (Doil et al. 2009). Notably, a recent study showed that RNF168-KO mice are fertile (Bohgaki et al. 2011), suggesting that, in contrast to its role in the somatic DDR, RNF168 may not be involved in RNF8dependent epigenetic programming on the sex chromosomes. It is our expectation that further examination of the role of DDR factors will elucidate unique gene activation mechanisms in germ cell development as well as novel links with epigenetic programming.

Preceding studies and our current study establish that meiotic sex chromosomes may serve as a model to dissect epigenetic programming because stereotypic programs are timely and spatially regulated (van der Heijden et al. 2007). MSCI is an essential step in meiotic progression, and cells with any defects in MSCI initiation are completely eliminated (Fernandez-Capetillo et al. 2003; Ichijima et al. 2011). This could underlie establishment of highly coordinated epigenetic programming on the sex chromosomes following the initiation of MSCI. Our results also provide insight into epigenetic programming by suggesting that silent modifications are not dependent on RNF8. Thus, silent and active epigenetic modifications are genetically separable on the sex chromosomes. Based on the stage of their appearance and disappearance, ubiquitinated H2A and H4K20mel may be closely linked to each other. Another layer of regulation may enable subsequent accumulation of H3K4me2 after the diplotene stage.

We identified H3K4me2 as a potential epigenetic memory on the sex chromosomes maintained from meiosis to post-meiotic spermatids. The role of $\mathrm{H} 3 \mathrm{~K} 4 \mathrm{me} 2$ as the mediator of epigenetic memory on mammalian sex chromosomes is somewhat akin to its suggested role in epigenetic inheritance in mammalian sperm and in the Caenorhabditis elegans germline, where H3K4me2 serves as the epigenetic memory for transgenerational inheritance (Hammoud et al. 2009; Katz et al. 2009; Brykczynska et al. 2010). It should be noted that deletion of an E2 ubiquitin-conjugating enzyme, HR6b, was shown to in- crease the level of H3K4me2 on mammalian meiotic sex chromosomes and derepress much of the sex chromosomelinked gene expression (Baarends et al. 2007; Mulugeta Achame et al. 2010). Using the Rnf8-KO, we found the opposite: The level of $\mathrm{H} 3 \mathrm{~K} 4 \mathrm{me} 2$ is depleted, and the expression of escape genes is repressed. Thus, the distinct roles between HR6b and RNF8 further suggest that gene silencing and escape gene activation are genetically separable on meiotic sex chromosomes. Further investigation of RNF8-dependent epigenetic programming should reveal hitherto unknown regulatory mechanisms of Kcr and histone replacement by $\mathrm{H} 2 \mathrm{AFZ}$ in the context of the epigenetic memory mediated by H3K4me2.

Although we found that RNF8 has a novel and important role in regulating escape genes in round spermatids, only a subset of escape genes is regulated by RNF8. One potential explanation for this observation is that there could be another mechanism besides the RNF8-dependent pathway that confers gene activation in round spermatids. One potential mechanism for alternative pathways could be regulation of histone acetylation. Indeed, we did not see any difference in the profiles of H4K8 acetylation and H4K16 acetylation in the round spermatids between the wild type and Rnf8-KO (Fig. 2P-S). These modifications are likely established on the sex chromosomes independently of RNF8.

Finally, our data suggest the essential role of sex chromosome-linked genes in fertility. RNF8 appears to significantly affect the regulation of escape genes on the Y chromosome. Although sequencing of the mouse Y chromosome is still incomplete and its genomic features remain unclear, several Y-linked genes were reported to function in post-meiotic germ cells. For instance, the loss of expression of the Y-linked Ssty gene family results in severe sperm defects and sterility due to extensive Yq deletion (Toure et al. 2005). Additionally, sperm from a Yq-deleted mouse (loss of the Ssty gene family) are able to produce offspring using intracytoplasmic sperm injection (ICSI), indicating that Y-linked gene families are necessary for normal function of sperm motility (Ward and Burgoyne 2006). Taken together, our data and preceding studies suggest that RNF8-dependent Y-linked genes play critical roles in sperm-related functions. Furthermore, reproductive functions of RNF8-dependent $\mathrm{X}$-linked genes are reported for Rhox 11 and Samt1. These gene families are expressed in round spermatids and late steps of spermatids in normal mouse testes (Hogeveen and Sassone-Corsi 2005; Maclean et al. 2005; Yogo et al. 2012). In particular, Rhox11 regulates the induction of androgen (Maclean et al. 2005). It is clinically wellcharacterized that administration of androgen to patients with low-quality semen helps to increase sperm motility in humans (Brown 1975). Interestingly, another RNF8dependent escape gene, $A r$ (androgen receptor), is also significantly down-regulated in Rnf8-KO mice. The expression of $A r$ is crucial for maturation of spermatozoa within the epididymis in mice (O'Hara et al. 2011). Moreover, a cohort study of infertile men showed that mutations of $A R$ affect sperm motility and counts in humans (Lazaros et al. 2012). It is possible that the phenotypic abnormalities 
of Rnf8-KO mice are associated with low-quality sperm due to the down-regulation of androgen-related RNF8dependent genes. We anticipate that RNF8-dependent epigenetic programming is conserved in humans and that elucidation of the activation mechanism of RNF8-dependent escape genes will contribute to our understanding of human male infertility.

\section{Materials and methods}

\section{Mice}

The Rnf8-KO was generated previously from the embryonic stem cell line RRR260 (Bay Genomics) (Santos et al. 2010) and is on C57BL/6 backgrounds. The 53bp1-KO (Ward et al. 2003) is on a mixed background. For slide preparation, mutants and littermate controls were processed between 40 and $80 \mathrm{~d}$ of age post-partum.

\section{Spermatogenesis slide preparation}

Analysis of sex chromosomes during meiosis was performed using hypotonic treatment as described (Peters et al. 1997). In order to conserve the morphology of meiotic chromatin and the relative three-dimensional nuclear structure in mouse testes, analysis of sex chromosomes in round spermatids was performed using slides that were prepared as described (Namekawa et al. 2006; Namekawa and Lee 2011). To prepare paraffin blocks, testes were fixed with $4 \%$ paraformaldehyde in PBS, ethanoldehydrated, and embedded in paraffin. Six-micrometer paraffin sections were prepared with a microtome (Leica) and deparaffinized prior to immunostaining.

\section{Immunofluorescence microscopy of spermatogenesis slides}

Slides were incubated in PBT $(0.15 \%$ bovine serum albumin [BSA], $0.1 \%$ Tween 20 in PBS) for 60 min prior to overnight incubation at room temperature with the following antibodies: SCP3 (Abcam), 1:5000; H4K20me1 (Millipore), 1:250; H3K4me2 (Millipore), 1:250; H3K4me3 (Cell Signaling), 1:10,000; pan crotonyllysine (Kcr, PTM BioLab), 1:100; H2AFZ (Millipore), 1:400; 53BP1 (Novus), 1:100, RAP80 (Santa Cruz Biotechnology), 1:100; $\gamma \mathrm{H} 2 \mathrm{AX}$ (Millipore), 1:5000; monoubiquitinated histone H2A, clone E6C5 (Millipore), 1:100; ubiquitin conjugates (FK2, Enzo Life Sciences), ubiquitinated histone H2B (Medimabs) 1:500; H3K9me2 (Millipore), 1:250; H3K9me3 (Millipore), 1:250; CBX1 (Abcam), 1:200; CBX3 (Millipore), 1:500; H4K8ac (Millipore), 1:250; H4K16ac (Millipore), 1:250; and Protamine P1 (Briar Patch Biosciences), 1:100. Thereafter, slides were washed three times for $5 \mathrm{~min}$ each in PBS plus $0.1 \%$ Tween 20, incubated with secondary antibodies (Invitrogen or Jackson ImmunoResearch) at 1:500 for $60 \mathrm{~min}$ in PBT, washed in PBS plus $0.1 \%$ Tween 20, and mounted in Vectashield with DAPI. Details of immunofluorescence microscopy are described elsewhere (Namekawa and Lee 2011). All images of germ cells were acquired with a TE2000-E microscope (Nikon) and a CoolSNAPHQ camera (Photometrics). Image acquisition was performed using Phylum software (Improvision). Adobe Photoshop was used for composing figures. For the analysis of meiosis and round spermatids, we analyzed a minimum of 50 nuclei of pachytene spermatocytes or round spermatids per staining. Particular stages of primary spermatocytes were determined by staining for SCP3. To generate the line traces, we exported the adjusted images to the NIH's ImageJ software and performed the quantitative analysis along a single transect as shown. To compare the wild type and the Rnf8-KO, we normalized the relative intensity of each picture together to generate comparable line traces.

\section{Germ cell fractionation and microarray analysis}

Pachytene spermatocytes and round spermatids were enriched from three to four males from the wild type or Rnf8-KO via BSA gravity sedimentation (Bellve 1993), and $>95 \%$ enrichments were verified after DAPI staining under a fluorescent microscope, respectively. For microarray analysis, total RNAs from purified pachytene spermatocytes or round spermatids were examined on Affymetrix Gene 1.0 ST arrays. Data was analyzed using Agilent GeneSpring to identify gene probes that showed a more than twofold change with statistical significance $(P<0.05$, unpaired $t$-test) after multiple testing corrections with the Benjamini and Hochberg false discovery rate. Data were also analyzed using Affymetrix Expression Console software for the calculation of average expression levels of each chromosome, with each array normalized with the robust multichip array (RMA) algorithm. Two biological replicates (each consisting of purified germ cells from three or four mice) were analyzed. The microarray data have been uploaded to the Gene Expression Omnibus (GEO) database (http://www.ncbi.nlm.nih.gov/geo) with the accession number GSE39302. GeneSpring and Excel software were used to generate the figures. Functional annotation analysis of genes was based on gene ontology (GO) (Gene Ontology Consortium, http://www.geneontology.org). For this analysis, we eliminated functionally undefined gene sets described as physiological processes that are mostly assigned to Y-linked genes.

\section{ChIP-seq analysis}

ChIP-seq data GSM810678 (Round-spermatids_Kcro) were downloaded from GEO (http://www.ncbi.nlm.nih.gov/geo/query/ acc.cgi?acc=GSE32663) and converted to FASTQ files using sratoolkit.2.1.9-win32 (fastq-dump.exe). Bowtie 0.12.7 was used to align reads to the mouse genome $(\mathrm{mm}$ ) $)$. Average read density profiles were then calculated around TSSs for several subsets of genes. Figure 4A shows all NM_ refeseq genes: those located on chromosome $\mathrm{X}$, those located on autosomes (University of California at Santa Cruz annotation), highly expressed genes (Present call in all microarray replicates), and silent genes (Absent call in all microarray replicates) (Affymetrix annotation). Figure 4C shows X-linked genes down-regulated in the Rnf8-KO as listed in Supplemental Table S2; X-linked genes silenced by post-meiotic silencing are defined based on the recovery rate / the ratio of reactivation in round spermatids as compared with the degree of silencing in pachytene spermatocytes) as described previously (Namekawa et al. 2006). For this analysis, we considered a gene to be subject to post-meiotic silencing if it showed a recovery rate below 0.2 (Affymetrix annotation). To create average density plots, reads 2000 bases upstream of and downstream from start sites were shifted $75 \mathrm{bp}$ in the direction of each read, counted at each position, and normalized by the number of total mapped reads and number of genes in each subset. Reads belonging to the $\mathrm{X}$ and $\mathrm{Y}$ chromosomes were counted twice. The resulting graphs were smoothed in Matlab.

\section{Cell culture, siRNAs, and laser microirradiation}

Analysis using U2OS cells transfected with siRNAs was conducted as described previously (Zhang et al. 2009) unless otherwise noted. Briefly, cells were grown overnight on glass coverslips prior to transfection with siRNAs directed against LacZ (control) or RNF8 (5'-GGACAAUUAUGGACAACAA-3') 
(Zhang et al. 2012). At $48 \mathrm{~h}$ after transfection, cells were incubated with $10 \mu \mathrm{M}$ BrdU for $24 \mathrm{~h}$ and then microirradiated (355 nm) in stripes using an ArcturusXT laser capture microdissection system (Invitrogen). After $2 \mathrm{~h}$, cells were fixed (2\% paraformaldehyde in PBS for $20 \mathrm{~min}$ at room temperature). Subsequent washes and incubations with antibodies were performed as described previously (Zhang et al. 2009). Coverslips containing cells were mounted with Vectashield containing DAPI and examined using a Zeiss Axiovert 200M microscope.

\section{Extraction of cells and Western blotting}

Whole testes were homogenized using a Polytrone homogenizer with RIPA buffer containing protease inhibitor Complete (Roche) and Phosphatase Inhibitor Cocktail 3 (Sigma). After centrifugation, the protein concentration was measured, and whole lysate and pellets were mixed together and boiled with sample buffer for SDS-PAGE. Western blotting was performed with the following antibodies: histone H3 (Millipore), 1:2000; H2A (Millipore), 1:2000; ubiquitinated histone H2B (Millipore), 1:2000; H4K8ac (Millipore), 1:1000; H4K16ac (Millipore), 1:100; and Protamine P1 (Briar Patch Biosciences), 1:50.

\section{$R T-P C R$}

For real-time RT-PCR, RNA was prepared by Trizol, DNasetreated (Ambion), reverse-transcribed using SuperScript III first strand synthesis system (Invitrogen), and then random hexamerprimed. PCR was carried out with the $\mathrm{S} 1000$ system (Bio-Rad) using the following conditions: $3 \mathrm{~min}$ at $95^{\circ} \mathrm{C},\left(30 \mathrm{sec}\right.$ at $95^{\circ} \mathrm{C}$, $30 \mathrm{sec}$ at $60^{\circ} \mathrm{C}$, and $1 \mathrm{~min}, 72^{\circ} \mathrm{C}$ ) for 27 cycles. $\beta$-Actin expression was used as a positive control. Forward and reverse primers $\left(5^{\prime}\right.$ to $\left.3^{\prime}\right)$ and product sizes were as follows: $\beta$-actin, CCGTGAAAA GATGACCCAG and TAGCCACGCTCGGTCAGG, 249 bp; LOC100040188, TGACAGCGTCTATGGACAGG and CAAC CCCACTCCAGTTGTC, 182 bp; LOC100041223, AGGTCA ACTGCCAACAAACC and AGCCATCTTTCCCCTCAAAT, 209 bp; Srsy, AAAAGCCCCTTCTGACCAAT and TGGGAATC TCATGAGGAAGG 151 bp; Ssty1, TGTGGCCTGGTCTGTAT CAA and ATATCCCAGGGACACAGCAC, $197 \mathrm{bp}$; and Ssty2, CTCCCAACCCATAACCATTG and CATTGCCTGGGACT GAAGAT, 102 bp.

\section{ChIP-PCR analysis}

Round spermatids were enriched from six males from the wild type or Rnf8-KO via BSA gravity sedimentation (Bellve 1993). Purified round spermatids were lysed and digested by micrococcal nuclease to obtain mononucleosomal DNAs. Prior to immunoprecipitation, Dynabeads of protein G (Invitrogen) were incubated with $20 \mu \mathrm{L}$ of polyclonal anti-rabbit pan crotonyllysine (Kcr, PTM BioLab) antibody or $10 \mu \mathrm{L}$ of normal rabbit IgG as a negative control (Millipore), respectively. The mononucelosomal DNA fragments were immunoprecipitated by protein G-coupled normal rabbit IgG and Kcr antibody overnight at $4^{\circ} \mathrm{C}$. After DNA extraction by conventional phenol-chloroform treatment, enriched mononucelosomal DNAs were purified by ethanol precipitation. ChIP-enriched mononucleosomal DNAs were subsequently amplified using the following conditions: $2 \mathrm{~min}$ at $95^{\circ} \mathrm{C},\left(30 \mathrm{sec}\right.$ at $95^{\circ} \mathrm{C}, 20 \mathrm{sec}$ at $58^{\circ} \mathrm{C}$, and $2 \mathrm{~min}$ at $72^{\circ} \mathrm{C}$ ) for 35 cycles using the $\mathrm{S} 1000$ system (Bio-Rad). The concentration of each ChIP-enriched DNA fragment was measured using an Agilent 2100 Bioanalyzer and adjusted to a final concentration of $0.5 \mathrm{ng}$ for ChIP-PCR amplification, and Input was used as a positive control. PCR primers were designed to cover the TSSs of each gene. Forward and reverse primers (5' to $\left.3^{\prime}\right)$ and product sizes were as follows: Agtr2, TAGGTTGAAGGCTCCC CAGT and CTGCTGTATGTTCCCCTTCC, 184 bp; Ccdc120 (Dxlmx50), GTCCAGGCCCTAGCTTTCCT and GTGACCC TAGCCCTGGAAG, 153 bp; Huwe1 (Ureb1), TGAAGAAAGG CCTCTTGAAA and CCAGTTGTTGCTGTTGGACT, 179 bp; Lanc13, CACGTCCCAGGCCTTCTG and GCAGAGCTAGG AATGCGTGT, 198 bp; Mageh1, AAGGAACCAGTCGCTTT CAG and GGGAGAGTCCCACTTCCTCT, $172 \mathrm{bp}$; Prame, ACATTTCAGTCTTTGCTGTTTTT and CTGGGCTGTGAGA GGAATTT, 157 bp; 4930480E11Rik, CATATGAAAGTTGTAG TAACCTCCAC and GAAGACCAAATATTAGTGACAACCAA, $150 \mathrm{bp}$; Rhox11, GCACACTCTTGTGGTTTCCA and AAGT TCTACCCCGTGTGTGC, 175 bp; Mage-K1 (4930550L24Rik), GCCCCTCCTTAGTTCCAGAT and CCTGCAATGCCTCC TTCAG, $182 \mathrm{bp}$; and $S s \times b 10$, TCAAACAGATCGAGAAGTA AGCA and GCCAAACCCTTTGAATTCCT, 172 bp.

\section{Acknowledgments}

We thank Yuya Ogawa, Norishige Yamada, and Kazuteru Hasegawa for discussion and helpful comments regarding the manuscript; Shawn Smith for help with the microarray analysis; Yosuke Ichijima and Misako Ichijima for technical assistance; and Serenity Curtis and Tyler Broering for editing the manuscript. This work was supported by the Lalor foundation postdoctoral fellowship (to H.-S.S.); the Developmental Fund, Trustee Grant and Research Innovation Funding at Cincinnati Children's Hospital Medical Center (to S.H.N.); the Basil O'Connor Starter Scholar Award from the March of Dimes Foundation (to S.H.N.); the NCI (NIH) Intramural Research Program (to A.N.); and NIH grants HL098691 (to A.B.), CA092312 (to J. C.), HL085587 (to P.R.A.), and GM098605 (to S.H.N.).

\section{References}

An JY, Kim EA, Jiang Y, Zakrzewska A, Kim DE, Lee MJ, MookJung I, Zhang Y, Kwon YT. 2010. UBR2 mediates transcriptional silencing during spermatogenesis via histone ubiquitination. Proc Natl Acad Sci 107: 1912-1917.

Baarends WM, Wassenaar E, van der Laan R, Hoogerbrugge J, Sleddens-Linkels E, Hoeijmakers JH, de Boer P, Grootegoed JA. 2005. Silencing of unpaired chromatin and histone H2A ubiquitination in mammalian meiosis. Mol Cell Biol 25: 1041-1053.

Baarends WM, Wassenaar E, Hoogerbrugge JW, Schoenmakers S, Sun ZW, Grootegoed JA. 2007. Increased phosphorylation and dimethylation of XY body histones in the Hr6b-knockout mouse is associated with derepression of the $\mathrm{X}$ chromosome. J Cell Sci 120: 1841-1851.

Barski A, Cuddapah S, Cui K, Roh TY, Schones DE, Wang Z, Wei G, Chepelev I, Zhao K. 2007. High-resolution profiling of histone methylations in the human genome. Cell 129: 823-837.

Beck DB, Oda H, Shen SS, Reinberg D. 2012. PR-Set7 and H4K20me1: At the crossroads of genome integrity, cell cycle, chromosome condensation, and transcription. Genes Dev 26: 325-337.

Bellve AR. 1993. Purification, culture, and fractionation of spermatogenic cells. Methods Enzymol 225: 84-113.

Berletch JB, Yang F, Disteche CM. 2010. Escape from X inactivation in mice and humans. Genome Biol 11: 213. doi: 10.1186/gb-2010-11-6-213.

Bohgaki T, Bohgaki M, Cardoso R, Panier S, Zeegers D, Li L, Stewart GS, Sanchez O, Hande MP, Durocher D, et al. 2011. Genomic instability, defective spermatogenesis, immunodeficiency, and cancer in a mouse model of the RIDDLE syndrome. PLoS Genet 7: e1001381. doi: 10.1371/journal.pgen.1001381. 
Brown JS. 1975. The effect of orally administered androgens on sperm motility. Fertil Steril 26: 305-308.

Brykczynska U, Hisano M, Erkek S, Ramos L, Oakeley EJ, Roloff TC, Beisel C, Schubeler D, Stadler MB, Peters AH. 2010. Repressive and active histone methylation mark distinct promoters in human and mouse spermatozoa. Nat Struct Mol Biol 17: 679-687.

de Napoles M, Mermoud JE, Wakao R, Tang YA, Endoh M, Appanah R, Nesterova TB, Silva J, Otte AP, Vidal M, et al. 2004. Polycomb group proteins Ring1A/B link ubiquitylation of histone $\mathrm{H} 2 \mathrm{~A}$ to heritable gene silencing and $\mathrm{X}$ inactivation. Dev Cell 7: 663-676.

Doil C, Mailand N, Bekker-Jensen S, Menard P, Larsen DH, Pepperkok R, Ellenberg J, Panier S, Durocher D, Bartek J, et al. 2009. RNF168 binds and amplifies ubiquitin conjugates on damaged chromosomes to allow accumulation of repair proteins. Cell 136: 435-446.

Feng L, Chen J. 2012. The E3 ligase RNF8 regulates KU80 removal and NHEJ repair. Nat Struct Mol Biol 19: 201-206.

Fernandez-Capetillo O, Mahadevaiah SK, Celeste A, Romanienko PJ, Camerini-Otero RD, Bonner WM, Manova K, Burgoyne P, Nussenzweig A. 2003. H2AX is required for chromatin remodeling and inactivation of sex chromosomes in male mouse meiosis. Dev Cell 4: 497-508.

Francis NJ, Kingston RE, Woodcock CL. 2004. Chromatin compaction by a polycomb group protein complex. Science 306: 1574-1577.

Gendrel AV, Heard E. 2011. Fifty years of X-inactivation research. Development 138: 5049-5055.

Greaves IK, Rangasamy D, Devoy M, Marshall Graves JA, Tremethick DJ. 2006. The X and Y chromosomes assemble into H2A.Z-containing [corrected] facultative heterochromatin [corrected] following meiosis. Mol Cell Biol 26: 53945405.

Hammoud SS, Nix DA, Zhang H, Purwar J, Carrell DT, Cairns BR. 2009. Distinctive chromatin in human sperm packages genes for embryo development. Nature 460: 473-478.

Hogeveen KN, Sassone-Corsi P. 2005. Homeobox galore: When reproduction goes RHOX and roll. Cell 120: 287-288.

Huen MS, Grant R, Manke I, Minn K, Yu X, Yaffe MB, Chen J. 2007. RNF8 transduces the DNA-damage signal via histone ubiquitylation and checkpoint protein assembly. Cell 131: 901-914.

Ichijima Y, Ichijima M, Lou Z, Nussenzweig A, Camerini-Otero RD, Chen I, Andreassen PR, Namekawa SH. 2011. MDC1 directs chromosome-wide silencing of the sex chromosomes in male germ cells. Genes Dev 25: 959-971.

Ichijima Y, Sin HS, Namekawa SH. 2012. Sex chromosome inactivation in germ cells: Emerging roles of DNA damage response pathways. Cell Mol Life Sci 69: 2559-2572.

Inagaki A, Schoenmakers S, Baarends WM. 2010. DNA double strand break repair, chromosome synapsis and transcriptional silencing in meiosis. Epigenetics 5: 255-266.

Katz DJ, Edwards TM, Reinke V, Kelly WG. 2009. A C. elegans LSD1 demethylase contributes to germline immortality by reprogramming epigenetic memory. Cell 137: 308-320.

Kohlmaier A, Savarese F, Lachner M, Martens J, Jenuwein T, Wutz A. 2004. A chromosomal memory triggered by Xist regulates histone methylation in $\mathrm{X}$ inactivation. PLoS Biol 2: E171. doi: 10.1371/journal.pbio.0020171.

Kolas NK, Chapman JR, Nakada S, Ylanko J, Chahwan R, Sweeney FD, Panier S, Mendez M, Wildenhain J, Thomson TM, et al. 2007. Orchestration of the DNA-damage response by the RNF8 ubiquitin ligase. Science 318: 1637-1640.

Lazaros L, Xita N, Takenaka A, Sofikitis N, Makrydimas G, Stefos T, Kosmas I, Zikopoulos K, Hatzi E, Georgiou I. 2012.
Semen quality is influenced by androgen receptor and aromatase gene synergism. Hum Reprod doi: 10.1093/humrep/ des334.

Lee JT. 2011. Gracefully ageing at 50, X-chromosome inactivation becomes a paradigm for RNA and chromatin control. Nat Rev Mol Cell Biol 12: 815-826.

Lu LY, Wu J, Ye L, Gavrilina GB, Saunders TL, Yu X. 2010. RNF8-dependent histone modifications regulate nucleosome removal during spermatogenesis. Dev Cell 18: 371-384.

Luijsterburg MS, Acs K, Ackermann L, Wiegant WW, BekkerJensen S, Larsen DH, Khanna KK, van Attikum H, Mailand N, Dantuma NP. 2012. A new non-catalytic role for ubiquitin ligase RNF8 in unfolding higher-order chromatin structure. EMBO I 31: 2511-2527.

Maclean JA, Chen MA, Wayne CM, Bruce SR, Rao M, Meistrich ML, Macleod C, Wilkinson MF. 2005. Rhox: A new homeobox gene cluster. Cell 120: 369-382.

Mailand N, Bekker-Jensen S, Faustrup H, Melander F, Bartek J, Lukas C, Lukas J. 2007. RNF8 ubiquitylates histones at DNA double-strand breaks and promotes assembly of repair proteins. Cell 131: 887-900.

Mueller JL, Mahadevaiah SK, Park PJ, Warburton PE, Page DC, Turner JM. 2008. The mouse X chromosome is enriched for multicopy testis genes showing postmeiotic expression. Nat Genet 40: 794-799.

Mulugeta Achame E, Wassenaar E, Hoogerbrugge JW, SleddensLinkels E, Ooms M, Sun ZW, van IJcken WF, Grootegoed JA, Baarends WM. 2010. The ubiquitin-conjugating enzyme HR6B is required for maintenance of $\mathrm{X}$ chromosome silencing in mouse spermatocytes and spermatids. BMC Genomics 11: 367. doi: 10.1186/1471-2164-11-367.

Namekawa SH, Lee JT. 2011. Detection of nascent RNA, singlecopy DNA and protein localization by immunoFISH in mouse germ cells and preimplantation embryos. Nat Protoc 6: $270-284$.

Namekawa SH, Park PJ, Zhang LF, Shima JE, McCarrey JR, Griswold MD, Lee JT. 2006. Postmeiotic sex chromatin in the male germline of mice. Curr Biol 16: 660-667.

O'Hara L, Welsh M, Saunders PT, Smith LB. 2011. Androgen receptor expression in the caput epididymal epithelium is essential for development of the initial segment and epididymal spermatozoa transit. Endocrinology 152: 718729.

Payer B, Lee JT, Namekawa SH. 2011. X-inactivation and X-reactivation: Epigenetic hallmarks of mammalian reproduction and pluripotent stem cells. Hum Genet 130: 265280.

Peters AH, Plug AW, van Vugt MJ, de Boer P. 1997. A dryingdown technique for the spreading of mammalian meiocytes from the male and female germline. Chromosome Res 5: 6668.

Rothkamm K, Lobrich M. 2003. Evidence for a lack of DNA double-strand break repair in human cells exposed to very low X-ray doses. Proc Natl Acad Sci 100: 5057-5062.

Santos MA, Huen MS, Jankovic M, Chen HT, López-Contreras AJ, Klein IA, Wong N, Barbancho JL, Fernandez-Capetillo O, Nussenzweig MC, et al. 2010. Class switching and meiotic defects in mice lacking the E3 ubiquitin ligase RNF8. J Exp Med 207: 973-981.

Schones DE, Cui K, Cuddapah S, Roh TY, Barski A, Wang Z, Wei G, Zhao K. 2008. Dynamic regulation of nucleosome positioning in the human genome. Cell 132: 887-898.

Shanbhag NM, Rafalska-Metcalf IU, Balane-Bolivar C, Janicki SM, Greenberg RA. 2010. ATM-dependent chromatin changes silence transcription in cis to DNA double-strand breaks. Cell 141: 970-981. 
Sin et al.

Sin HS, Ichijima Y, Koh E, Namiki M, Namekawa SH. 2012. Human postmeiotic sex chromatin and its impact on sex chromosome evolution. Genome Res 22: 827-836.

Song R, Ro S, Michaels JD, Park C, McCarrey JR, Yan W. 2009. Many X-linked microRNAs escape meiotic sex chromosome inactivation. Nat Genet 41: 488-493.

Talasz H, Lindner HH, Sarg B, Helliger W. 2005. Histone H4lysine 20 monomethylation is increased in promoter and coding regions of active genes and correlates with hyperacetylation. J Biol Chem 280: 38814-38822.

Tan M, Luo H, Lee S, Jin F, Yang JS, Montellier E, Buchou T, Cheng Z, Rousseaux S, Rajagopal N, et al. 2011. Identification of 67 histone marks and histone lysine crotonylation as a new type of histone modification. Cell 146: 1016-1028.

Toure A, Clemente EJ, Ellis P, Mahadevaiah SK, Ojarikre OA, Ball PA, Reynard L, Loveland KL, Burgoyne PS, Affara NA. 2005. Identification of novel Y chromosome encoded transcripts by testis transcriptome analysis of mice with deletions of the Y chromosome long arm. Genome Biol 6: R102. doi: 10.1186/gb-2005-6-12-r102.

Turner JM. 2007. Meiotic sex chromosome inactivation. Development 134: 1823-1831.

Turner JM, Mahadevaiah SK, Ellis PJ, Mitchell MJ, Burgoyne PS. 2006. Pachytene asynapsis drives meiotic sex chromosome inactivation and leads to substantial postmeiotic repression in spermatids. Dev Cell 10: 521-529.

van der Heijden GW, Derijck AA, Posfai E, Giele M, Pelczar P, Ramos L, Wansink DG, van der Vlag J, Peters AH, de Boer P. 2007. Chromosome-wide nucleosome replacement and H3.3 incorporation during mammalian meiotic sex chromosome inactivation. Nat Genet 39: 251-258.

Wang B, Elledge SJ. 2007. Ubc13/Rnf8 ubiquitin ligases control foci formation of the Rap80/Abraxas/Brca1/Brcc36 complex in response to DNA damage. Proc Natl Acad Sci 104: 2075920763.

Ward MA, Burgoyne PS. 2006. The effects of deletions of the mouse Y chromosome long arm on sperm function-intracytoplasmic sperm injection (ICSI)-based analysis. Biol Reprod 74: 652658.

Ward IM, Minn K, van Deursen J, Chen J. 2003. p53 Binding protein $53 \mathrm{BP} 1$ is required for DNA damage responses and tumor suppression in mice. Mol Cell Biol 23: 2556-2563.

Wu J, Huen MS, Lu LY, Ye L, Dou Y, Ljungman M, Chen J, Yu X. 2009. Histone ubiquitination associates with BRCA1-dependent DNA damage response. Mol Cell Biol 29: 849-860.

Yan W, McCarrey JR. 2009. Sex chromosome inactivation in the male. Epigenetics 4: 452-456.

Yogo K, Tojima H, Ohno JY, Ogawa T, Nakamura N, Hirose S, Takeya T, Kohsaka T. 2012. Identification of SAMT family proteins as substrates of MARCH11 in mouse spermatids. Histochem Cell Biol 137: 53-65.

Zhang F, Fan Q, Ren K, Andreassen PR. 2009. PALB2 functionally connects the breast cancer susceptibility proteins BRCA1 and BRCA2. Mol Cancer Res 7: 1110-1118.

Zhang YE, Vibranovski MD, Landback P, Marais GA, Long M. 2010. Chromosomal redistribution of male-biased genes in mammalian evolution with two bursts of gene gain on the $\mathrm{X}$ chromosome. PLOS Biol 8: e1000494. doi: 10.1371/journal. pbio.1000494.

Zhang F, Bick G, Park JY, Andreassen PR. 2012. MDC1 and RNF8 function in a pathway that directs BRCA1-dependent localization of PALB2 required for homologous recombination. J Cell Sci doi: 10.1242/jcs.111872. 


\section{Erratum}

Genes \& Development 26: 2737-2748 (2012)

RNF8 regulates active epigenetic modifications and escape gene activation from inactive sex chromosomes in post-meiotic spermatids

Ho-Su Sin, Artem Barski, Fan Zhang, Andrey V. Kartashov, Andre Nussenzweig, Junjie Chen, Paul R. Andreassen, and Satoshi H. Namekawa

In the above-mentioned article, the affiliations for coauthor Paul R. Andreassen should have been corrected as follows:

Department of Pediatrics, University of Cincinnati College of Medicine, Cincinnati, Ohio 49229, USA; Division of Experimental Hematology and Cancer Biology, Cincinnati Children's Hospital Medical Center, Cincinnati, Ohio 45229, USA.

We apologize for the oversight. 


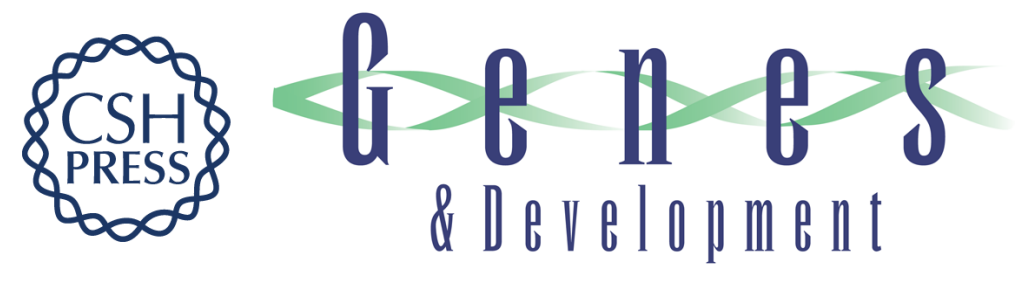

\section{RNF8 regulates active epigenetic modifications and escape gene activation from inactive sex chromosomes in post-meiotic spermatids}

Ho-Su Sin, Artem Barski, Fan Zhang, et al.

Genes Dev. 2012, 26:

Access the most recent version at doi:10.1101/gad.202713.112

\section{Supplemental http://genesdev.cshlp.org/content/suppl/2012/12/18/26.24.2737.DC1 \\ Material}

Related Content

RNF8 regulates active epigenetic modifications and escape gene activation from inactive sex chromosomes in post-meiotic spermatids

Ho-Su Sin, Artem Barski, Fan Zhang, et al.

Genes Dev. January, 2013 27: 116

References This article cites 58 articles, 18 of which can be accessed free at:

http://genesdev.cshlp.org/content/26/24/2737.full.html\#ref-list-1

Articles cited in:

http://genesdev.cshlp.org/content/26/24/2737.full.html\#related-urls

\section{License}

Email Alerting

Service

Receive free email alerts when new articles cite this article - sign up in the box at the top

right corner of the article or click here.

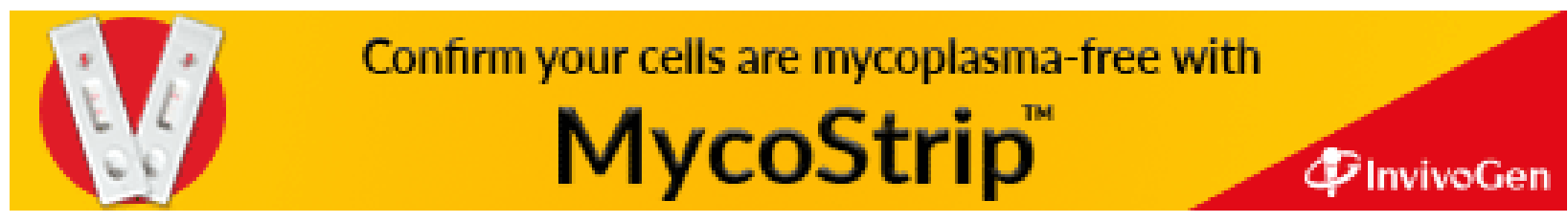

